Conclusions The clinical defining criteria for inflammation (SIRS criteria) do not equate to established biochemical indices of inflammation in cardiac surgery patients; hence the criteria alone should not be used to assess inflammation in this patient population.

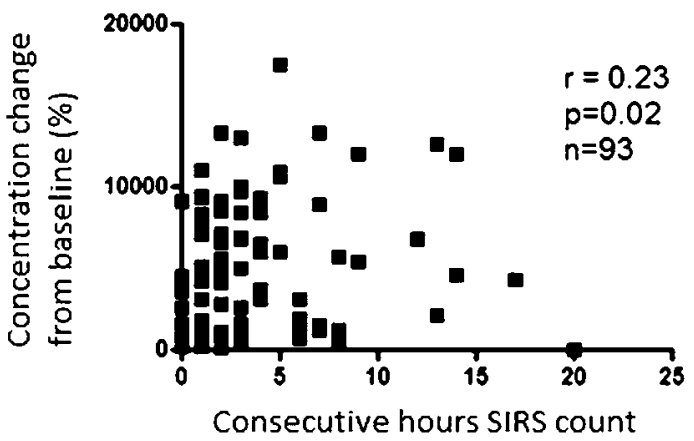

Abstract P70 Figure 1 Correlation between consecutive number of hours in which patients scored $\leq 2$ SIRS criteria and percentage change from baseline concentration of CRP. CRP was measured in plasma samples using ELISA. Data analysed using Spearman's rank correlation. $\mathrm{r}=$ correlation, $\mathrm{SIRS}=$ systemic inflammatory response syndrome.

\section{P71 RELATIONSHIP BETWEEN QUADRICEPS RECTUS FEMORIS CROSS-SECTIONAL AREA AND HEALTH RELATED QUALITY OF LIFE IN PATIENTS FOLLOWING CRITICAL ILLNESS}

doi:10.1136/thoraxjn-2011-201054c.71

${ }^{1,2} \mathrm{~B}$ Connolly, ${ }^{1} \mathrm{~J}$ Moxham, ${ }^{1,2} \mathrm{~N}$ Hart. ${ }^{1}$ Department of Asthma, Allergy \& Respiratory Science, Division of Asthma, Allergy and Lung Biology, King's College London, London, UK; ${ }^{2}$ Guy's \& St Thomas' NHS Foundation Trust and King's College London, National Institute of Health Research Comprehensive Biomedical Research Centre, London, UK

Introduction Quadriceps rectus femoris cross-sectional area ( $\left.\mathrm{RF}_{\mathrm{CSA}}\right)$ is considered a useful marker of quadriceps strength with a $20 \%$ reduction in $\mathrm{RF}_{\mathrm{CSA}}$ observed in critically ill patients at 10 days after admission to the intensive care unit (ICU). This has clinical importance in patients following the acute critical illness episode as it is postulated that quadriceps muscle wasting reduces quadriceps muscle strength and as a consequence impairs physical activity and health-related quality of life (HROL). We therefore hypothesised that $\mathrm{RF}_{\mathrm{CSA}}$ would have a direct relationship with HROL.

Method Patients were assessed within $48 \mathrm{~h}$ of discharge from the ICU to the ward as part of an ongoing multicentre randomised controlled trial. $\mathrm{RF}_{\mathrm{CSA}}$ was determined using real-time B-mode ultrasonography using an $8 \mathrm{MHz} 5.6 \mathrm{~cm}$ linear transducer (PLM805, Toshiba Medical Systems Ltd, Crawley, UK) at a distance three-fifths from anterior superior iliac spine to the superior patellar border. HROL was measured using the self-reported hospital anxiety and depression (HAD) scale and the short form-36 v2 (SF-36) questionnaire. Higher scores indicate better HROL from the SF-36 questionnaire and lower scores indicate better HROL from the HAD scale.

Results 17 post critical care patients were recruited. Mean age was $60.7 \pm 14.9$ years with $64.7 \%(n=11)$ female. Mean body mass index (BMI) was $26.0 \pm 6.4 \mathrm{~kg} / \mathrm{m}^{2}$ and fat-free mass index (FFMI) was $16.8 \pm 3.9 \mathrm{~kg} / \mathrm{m}^{2}$. The correlations between $\mathrm{RF}_{\mathrm{CSA}}$ and HRQL are shown in Abstract P71 table 1.

Abstract P71 Table 1 Relationships between $\mathrm{RF}_{\mathrm{CSA}}$ and HROL

\begin{tabular}{lcl}
\hline & r Value & p Value \\
\hline HAD & -0.6 & 0.01 \\
SF-36 PF & 0.24 & NS \\
SF-36 MF & 0.76 & 0.0005
\end{tabular}

$\mathrm{p}$ and $\mathrm{r}$ values derived from Spearman's correlation coefficient.

HAD, Hospital Anxiety and Depression scale; HRQL, health related quality of life; $\mathrm{RF}_{\mathrm{CSA}}$, rectus femoris cross-sectional area; SF-36 MF, Short Form 36 Mental Functioning domain score; SF-36 PF, Short Form 36 Physical Functioning domain score.
Conclusion $\mathrm{RF}_{\mathrm{CSA}}$ was correlated with $\mathrm{HROL}$, including $\mathrm{HAD}$ scale and the SF-36 mental functioning domain, but there was no relationship with the SF-36 physical function domain and $\mathrm{RF}_{\mathrm{CSA}}$. Although this was an unexpected finding, it reflects the limitations of the SF-36 physical function domain to separate those patients that have a marked reduction in independent physical activity following discharge from ICU. Further studies are required to assess the relationship between muscle wasting, strength, physical activity and quality of life in these patients following critical illness.

\section{P72 RELATIONSHIP BETWEEN QUADRICEPS RECTUS FEMORIS ANATOMICAL CROSS-SECTIONAL AREA, PHYSIOLOGICAL CROSS-SECTIONAL AREA AND PENNATION ANGLE IN HEALTHY SUBJECTS}

doi:10.1136/thoraxjnl-2011-201054c.72

${ }^{1,2} \mathrm{~B}$ Connolly, ${ }^{3} \mathrm{~A}$ Lunt, ${ }^{1} \mathrm{~J}$ Moxham, ${ }^{1,2} \mathrm{~N}$ Hart. ${ }^{1}$ Department of Asthma, Allergy \& Respiratory Science, Division of Asthma, Allergy and Lung Biology, King's College London, London, UK; ' ${ }^{2}$ uyy's \& St Thomas' NHS Foundation Trust and King's College London, National Institute of Health Research Comprehensive Biomedical Research Centre, London, UK; ${ }^{3}$ Department of Child Health, Division of Asthma, Allergy and Lung Biology, King's College London, London, UK

Introduction Although quadriceps rectus femoris anatomical crosssectional area $\left(\mathrm{RF}_{\mathrm{ACSA}}\right)$ has been shown to correlate with both volitional and non-volitional measures of quadriceps strength, this only incorporates the cross-sectional muscle mass and disregards the contribution of fibre orientation to the force generating capacity of the muscle. We therefore hypothesised that quadriceps rectus femoris physiological cross-sectional area $\left(\mathrm{RF}_{\mathrm{PCSA}}\right)$, which incorporates both $R F_{A C S A}$ and rectus femoris pennation angle $\left(R F_{P A}\right)$ would demonstrate a stronger relationship with, and be more representative of, quadriceps strength.

Method 21 healthy adults were recruited, 9 of whom were males, median (IOR) age $31(25-37)$ years. $\mathrm{RF}_{\mathrm{ACSA}}$ and $\mathrm{RF}_{\mathrm{PA}}$ were determined using real-time B-mode ultrasonography using an $8 \mathrm{MHz}$ $5.6 \mathrm{~cm}$ linear transducer (PLM805, Toshiba Medical Systems Ltd, Crawley, UK) at a point three-fifths distance from the anterior superior iliac spine to the superior patellar border. Values for $\mathrm{RF}_{\mathrm{PCSA}}$ were calculated from $\mathrm{RF}_{\mathrm{ACSA}}$ and $\mathrm{RF}_{\mathrm{PA}}$. $\mathrm{QMVC}$ was assessed using the technique of isometric maximum voluntary contraction and twitch tension ( $\mathrm{TwQ}$ ) following magnetic stimulation of the femoral nerve.

Results Males had significantly greater OMVC $(55.2 \pm 7.1 \mathrm{~kg}$ vs $36.3 \pm 7.5 \mathrm{~kg} ; \quad \mathrm{p}<0.0001), \quad \mathrm{TwO} \quad(12.6 \pm 3.6 \mathrm{~kg}$ vs $7.4 \pm 2.5 \mathrm{~kg}$; $\mathrm{p}=0.0002), \mathrm{RF}_{\mathrm{ACSA}}\left(8.9 \pm 1.7 \mathrm{~cm}^{2}\right.$ vs $\left.5.9 \pm 1.3 \mathrm{~cm}^{2} ; \mathrm{p}=0.0001\right)$ and $\mathrm{RF}_{\mathrm{PCSA}}\left(8.8 \pm 1.7 \mathrm{~cm}^{2}\right.$ vs $\left.5.8 \pm 1.2 \mathrm{~cm}^{2} ; \mathrm{p}=0.0001\right)$. There was no gender difference evident for $\mathrm{RF}_{\mathrm{PA}}\left(10.3(9.7-10.7)^{\circ}\right.$ vs 10.8 $\left.(9.8-12.1)^{\circ} ; \mathrm{p}=0.4\right)$ and percent muscle activation during OMVC $(83.9 \pm 9.3 \%$ vs $86.9 \pm 9.8 \% ; p=0.5)$. Identical correlations between $\mathrm{RF}_{\mathrm{ACSA}}$ and RFPCSA and both OMVC and TwQ were observed $(\mathrm{r}=0.7, \mathrm{p}=0.001)$. There were no significant correlations evident between $\mathrm{RF}_{\mathrm{PA}}$ and anthropomorphic measures of age, height, weight, body-mass index, fat-free mass or thigh length

Conclusion The pennation angle of the rectus femoris muscle was observed to be independent of anthropomorphic variables. Furthermore, and contrary to our original hypothesis, RF PCSA did not demonstrate a stronger relationship with quadriceps strength than $\mathrm{RF}_{\mathrm{ACSA}}$. This is an important finding for the clinician as the additional step of measuring the pennation angle of the muscle adds a complexity to this simple bedside test that would reduce its widespread clinical applicability. 